\title{
Physiological Responses Related to Clustered Nursing Interventions among Mechanically Ventilated Patients
}

\author{
Samar Abdel-Razek Younes EL-Sayed, Demonstrator \\ Critical Care and Emergency Nursing, Faculty of Nursing, Damanhour University \\ Nadia Taha Mohamed, Professor \\ Critical Care and Emergency Nursing, Faculty of Nursing, Alexandria University \\ Intessar Mohamed Ahmed, Lecturer \\ Critical Care and Emergency Nursing, Faculty of Nursing, Damanhour University
}

\author{
Amr Hassan Dahroug, Lecturer \\ Critical Care Medicine, Faculty of Medicine, Alexandria University
}

\begin{abstract}
Caring of the mechanically ventilated patients is a fundamental component of the nurse's clinical practice in the intensive care units (ICUs). Clustered nursing interventions are defined as group of interventions more than six interventions for every patient in one nursing interaction. Physiological responses may be an immediate response or long term effects of one or more of the body systems related to physiological condition and therapeutic interventions. Critical care nurses monitor patient's physiological parameters on a regular basis to assure the patient's stability. Objective: Determine physiological responses related to clustered nursing interventions among mechanically ventilated patients. Setting: The ICUs of the Alexandria main university hospital and the General ICU of Damanhur Medical National Institute Hospital. Subjects: A convenience sampling of 80 adult mechanically ventilated patients. Tools: Two tools were used to collect the data of this study. Tool one: "Physiological Response Measurement" and tool two: "Clustered Nursing Interventions Assessment Record. Results: A significant relation between mean physiological responses and clustered nursing care. Conclusion: Most of the physiological responses were affected significantly by the number of clustered nursing interventions, other are indicated by mean respiratory rate, mean systolic blood pressure and mean oxygen saturation. Recommendations: Continuous monitoring of the physiological responses during clustered nursing care performance. On-clustered nursing interventions should be performed and applied in the ICUs to prevent physiological response alterations related to clustered nursing interventions performance.
\end{abstract}

Keywords: Physiological Responses; Clustered Nursing Interventions; Mechanically Ventilated.

\section{Introduction}

Critically ill patients are those who are at high risk for actual or potential lifethreatening health problems. The more critically ill the patient is, the more likely he/she is to be highly vulnerable, unstable and complex, thereby requiring intense and vigilant nursing care. Those patients are prone to physiological and psychological stressors regards to their critical illness; they are vulnerable to many complications ${ }^{(1-4)}$.

Critical care nurses constitute the largest group of health care providers and their care influences patient outcomes. As they have agreed responsibility in the continuous assessment and monitoring of critically ill patients ${ }^{(5)}$. A lack of research use contributes to as many as $30 \%-40 \%$ of patients not receiving care, according to current scientific evidence, and some 20\%$25 \%$ of patients may receive potentially harmful care. About one third of hospital mortality occurs in critically ill patients inside intensive care unit (ICU) ${ }^{(6-7)}$. A Clinician has to consider many inter-related factors in making a prognosis regarding outcome in critically ill patients, including age, severity and irreversibility of the acute 
illness, physiological reserve and response to therapy ${ }^{(8.9)}$.

With improved knowledge of disease and the development of advanced medical technology, many patients in intensive care units receive sophisticated ventilator management. Critical illness is a lifethreatening multisystem process that can result in a significant morbidity or mortality $^{(10-15)}$.

Thus, intensive care unit is a specialized section of a hospital that provides comprehensive and continuous care for patients who are critically ill and who can benefit from treatment. Clustered nursing interventions are defined as group of interventions more than six interventions for each patient in one nursing interaction ${ }^{(16)}$.

Prolonged exposure of patients to change of physiological responses as a result of clustering nursing care events together rather than spacing them out over time that lead to many health problems and complications to the body systems of critically ill patients some common effects include: stress, anxiety, difficulty sleeping, diabetes, heart diseases and gastrointestinal problems such as stress ulcer and it is more common in ICU and that of clinically significant upper gastrointestinal bleeding from $2 \%$ to $6 \%$ and lead to hemodynamic instability and affect also oxygen consumption $^{(16,18-19)}$. Therefore, the hallmark of critical care nurse (CCN) is continuous monitoring and assessment of critically ill patients for early detection and management of life threatening problems experienced by critically ill patients ${ }^{(1,17,20)}$.

\section{Aim of the Study}

This study aims to determine the physiological responses related to clustered nursing interventions among mechanically ventilated patients.

\section{Research Question:}

What are the physiological responses related to clustered nursing interventions among mechanically ventilated patients?
Materials and Method

Materials

Design: A descriptive research design.

Setting: The study was conducted in the intensive care units of Alexandria Main University Hospital namely: The casualty intensive care unit (unit I) and the general intensive care unit (unit III). Damanhur Medical National Institute.

Subjects: The study subjects consisted of A convenience sample of 80 adult mechanically ventilated patients admitted to the previously mentioned setting aged 18 years and above, However, patients with the following criteria were excluded including lung disorder (e.g., chronic obstructive pulmonary disease, asthma, lung cancer, pneumonia, acute respiratory distress syndrome), and pregnancy.

Tools: In order to collect the necessary data, two tools were used:

Tool I: Physiological Response

\section{Measurement}

This tool was developed by the researcher after reviewing the relevant literature ${ }^{(15-19)}$ to measure physiological responses and includes the following parameters:

- End-tidal carbon dioxide

- Vital signs

- Oxygen saturation

Tool II: Clustered Nursing Interventions Assessment Record

Based on a pilot study of ten patients in different settings the most common procedures which were provided by the nurses in providing direct care for those patients were:

- Vital signs include (measurement of axillary's temperature, pulse and blood pressure).

- Central venous pressure measurement.

- Suctioning.

- Feeding (oral gastric tube, nasogastric tube).

- Laboratory Investigation sample (Routine sample, ABG sample)

- General care. 
- Reposition and range of motion exercises.

- Administration of medication.

This tool was developed by the researcher after reviewing the relevant Literature $^{(19-24)}$ to record:

- The type of nursing interventions which were provided by the nurses in providing direct care for those patients.

- The number of nursing interventions.

- The start time and duration of the each procedures.

Each item was marked as done or not done.

In addition, Patient's socio demographic and clinical data: It includes patient's age, sex, diagnosis, date of intensive care unit (ICU) admission, and date of institution of mechanical ventilation.

\section{Method}

- An official letter from the faculty of nursing was sent to the administrative authority in the intended study hospitals

- The study tools were developed by the researcher after reviewing the related literature.

- Tool II: "Clustered Nursing Interventions Assessment Record" was tested for reliability using Cronbach's alpha reliability method on sample of 18 subjects. The correlation coefficient was (0.730) which was accepted.

- A pilot study was done on $10 \%$ of sample before starting the data collection to test the feasibility and applicability of these tools, and they were excluded from the study.

- The two tools were reviewed by the jury of seven experts in medical specialty and nursing specialty for face and content validity.

- The data collection started at the beginning of January and was completed by April 2016.

\section{Ethical considerations:}

Informed written consent obtained from nurses and patients before conducting the study after explaining the aim of the study and the right to refuse to participate in the study emphasized to subjects for unconscious patient, the consent obtained from his/her relatives. Anonymity, privacy, confidentiality of the collected data obtained and the right to refuse to participate in the study assured.

\section{Statistical Analysis}

The statistical package for social science (SPSS) was utilized for data analysis and tabulation. The level of significance selected for this study was "P" equal or less than 0.05. Frequency tables and cross tabulations with percentages was used to illustrate the result of categorical data and tested by Fisher's Exact Test or Monte Carlo correction (MCP). Comparison of means was done by Student ttest. Comparison between two periods was done by Paired t-test. Correlation analysis: Pearson Correlation is used to test nature and strength of relation between two quantitative/ordinal variables.

\section{Results}

Table (1) shows the distribution of the critically ill patients according to their characteristics, about $48.75 \%$ of the study samples were from Damanhur Medical National Institute. More than half of the study samples $61.25 \%$ were male; while $38.75 \%$ were female the mean age of patients enrolled in the present study was $49.6 \pm 6.94$ years.

As regard to the length of stay in the intended ICUs, the majority of the study samples $41.25 \%$ stayed more than 2 weeks, while $25.0 \%$ stayed between 3 to 4 weeks. The mean length of stay was $16.8 \pm 5.4$ days. According to the duration of mechanical ventilation, more than half of the study samples $58.75 \%$ stayed on mechanical ventilation than 2 weeks, while only $8.75 \%$ were between 3 to 4 weeks. The mean duration of mechanical ventilation was $13.8 \pm 4.9$ days.

Concerning patients` diagnosis the most common diagnosis was related to neurological disorders which were represented by $35 \%$ of the study sample, while the least frequent diagnosis was related to others causes which include Road Traffic 
Accident, toxicology, drowning, and laryngeal carcinoma with percent of $5 \%$.

Table (2) shows distribution of the critically ill patients according to number of the clustered nursing interventions in the intended study ICUs. Mean values of number of clustered nursing interventions at ICU of Damanhur, ICU I and ICU III at Alexandria main university were $10.9 \pm 1.6,10.8 \pm 1.8$ and $10.8 \pm 1.3$. There was no significant difference between these units $(\mathrm{P}=0.483 \%)$.

Table (3) reveals the relationship between number of clustered nursing interventions and socio-demographic characteristics among the studied patients. It was found that insignificant relationship between age and sex and the number of clustered nursing interventions. Moreover, there was no significant relationship between duration of mechanical ventilation and length of stay in the intended ICUs and the number of clustered nursing interventions. On the other hand, there was a significant relationship between those who had neurological disorders and the other medical diagnosis, and physiological responses and number of clustered nursing interventions ( $\mathrm{p}=0.001)$.

Table (4) clarifies the mean value of the physiological parameters status before, during and after clustered nursing interventions performance.

Regarding the mean value of end tidal carbon dioxide, it can be noted from this table that the mean values of the end tidal carbon dioxide before, 5 minutes, 10 minutes during clustered nursing interventions, immediately after clustered nursing interventions performance and after 15 minutes from clustered nursing intervention performance were $27.8 \pm 9.5, \quad 31.5 \pm 20.4$, $32.0 \pm 10.2, \quad 37.7 \pm 11.2, \quad$ and $\quad 27.3 \pm 9.8$ respectively.

It was also noted in figure $\mathbf{1}$ the mean value of end tidal carbon dioxide immediately after clustered nursing interventions performance was significantly higher than the mean value before performing clustered nursing interventions ( $\mathrm{p}=0.001)$.

Concerning the mean respiratory rate, this table illustrates that the mean value of the respiratory rate before, 5 minutes, 10 minutes during clustered nursing interventions, immediately after clustered nursing interventions performance and after 15 minutes from clustered nursing intervention performance were $20.3 \pm 4.9, \quad 19.8 \pm 4.9$, $18.2 \pm 4.5, \quad 16.3 \pm 3.9, \quad$ and $21.5 \pm 4.5$ respectively.

It was also noted in figure 2 the mean value of respiratory rate immediately after clustered nursing interventions performance was significantly lower than the mean value before performing clustered nursing interventions $(\mathrm{p}=0.002)$.

Regarding the mean value of oxygen saturation, this table represents that the mean values of oxygen saturation before, 5 minutes, 10 minutes during clustered nursing interventions, immediately after clustered nursing interventions performance and after 15 minutes from clustered nursing interventions performance were $98.4 \pm 1.8$, $97.7 \pm 2.0,96.2 \pm 2.4,92.3 \pm 3.7$, and $98.1 \pm 1.9$ respectively.

It was also noted in figure $\mathbf{3}$ the mean value of oxygen saturation immediately after clustered nursing interventions performance was significantly lower than the mean value before performing clustered nursing interventions $(\mathrm{p}=0.028)$.

In relation to heart rate, it can be noted from this table reveals that the mean values of heart rate before, 5 minutes, 10 minutes during clustered nursing interventions, immediately after clustered nursing interventions performance and after 15 minutes from clustered nursing interventions performance were $94.3 \pm 18.7,96.3 \pm 19.4$, $99.5 \pm 21.2, \quad 103.4 \pm 22.5$, and $95.2 \pm 19.0$ respectively.

It was also noted in figure 4 the mean value of heart rate immediately after clustered nursing interventions performance was significantly higher than the mean value before performing clustered nursing interventions $(\mathrm{p}=0.022)$.

Regarding the mean value of systolic blood pressure, this table represents that the mean values of systolic blood pressure before, 5 minutes, 10 minutes during clustered nursing interventions, immediately after clustered nursing interventions 
performance and after 15 minutes from clustered nursing interventions performance were $130.4 \pm 27.0,130.4 \pm 27.1,130.2 \pm 26.9$, $137.5 \pm 28.0$, and $130.3 \pm 27.4$ respectively.

It was also noted in figure 5 the mean value of systolic blood pressure immediately after clustered nursing interventions performance was significantly higher than the mean value before performing clustered nursing interventions $(\mathrm{p}=0.005)$.

Concerning the mean body temperature, this table reflects that the mean values of body temperature before, 5 minutes, 10 minutes during clustered nursing interventions, immediately after clustered nursing interventions performance and after 15 minutes of clustered nursing interventions performance were $36.9 \pm 0.5, \quad 36.9 \pm 0.6$, $37.1 \pm 0.5, \quad 36.7 \pm 0.5, \quad$ and $\quad 36.9 \pm 0.4$ respectively.

It was also noted in figure 6 the mean value of body temperature immediately after clustered nursing interventions performance was lower than the mean value before performing clustered nursing interventions. The differences were not significant $(\mathrm{p}=0.086)$.

Table (5) reveals that relationship between physiological responses and number of clustered nursing interventions. It can be noted from this table that the mean respiratory rate and the mean systolic blood pressure increased with the increase number of clustered nursing care performance there were significant increase $(\mathrm{p}=0.003)$ and $(p=0.002)$, while the mean oxygen saturation decreased with the increase number of clustered nursing care performance, and it was significant $(\mathrm{p}=0.050)$.

Table (6) $\mathbf{a \& b}$ shows that the duration of each procedure (time taken for each procedure performed for critically ill patients by nurses), it was observed that the $92.5 \%$ of the patients under measuring vital signs, the time lasted less than 5 minutes with the mean duration of $3.88 \pm .51$, while $83.8 \%$ of central venous pressure measuring the time lasted between 5-10 minutes with the mean duration of $4.95 \pm 2.35$ minutes, also it was observed that $45.0 \%$ of the patients under bed bathing lasted more than 10 minutes with the mean duration of $8.41 \pm 7.54$ minutes. It also shows that there was a negative correlation between duration of measuring central ven r-.327, p.003 and also, there was a negative correlation between duration of bathing and oxygen saturation value r-.256, p.022, while there was a positive correlation between duration of suctioning and level of respiratory rate r.236, p.035 respectively.

\section{Discussion}

Results of the current study showed that there was no significant difference between the number of clustered nursing intervention performance and patient's age and sex. This finding may be due to the fact that critical care nurses provided nursing care regardless patient's age and sex. This finding is in agreement with Al Sutariet al. (2014) ${ }^{(24)}$ who found that there was no significant difference between younger and older patients and nursing procedures performed. Also, Max et al. $(2014)^{(25)}$ reported that there was no significant difference between nursing procedural performance and patient's age and sex

Findings of the present study revealed that there was a significant relationship between patients` neurological disorders and physiological responses regarding number of clustered nursing interventions performance

The finding of the present study is in congruence with Olson et al. (2013) $)^{(26)}$ in a study titled the effects of nursing interventions on intracranial pressure. It was concluded that a wide variety of nursing interventions performance for neurological patients were affected directly on intracranial pressure and physiological parameters. Moreover, Ugras et al. $(2014)^{(27)}$ in a study titled factors affecting intracranial pressure and nursing interventions. They concluded that one of the factors associated with increased intracranial pressure is clustering of all nursing interventions within the same time period.

Regarding the mean patient's end tidal carbon dioxide $\left(\mathrm{ETCO}_{2}\right)$, results of current study denoted that the mean patient's $\mathrm{ETCO}_{2}$ increased during and immediately after clustered nursing interventions 
performance compared to before performing clustered nursing interventions and return to baseline after 15 minutes from clustered nursing interventions performance. This finding may be due to the stress induced by the effect of clustered nursing interventions. This finding is supported by Genzler et al. $(2013)^{(23)}$ in a study titled end tidal carbon dioxide as a measure of stress response to clustered nursing intervention in neurologic patients. The study reported that mechanically ventilated patients who had six or more clustered interventions experienced a higher mean change in $\mathrm{ETCO}_{2}$ than patients who received fewer than six interventions. While, this finding is in opposition to Szabo et al. (2014) $)^{(22)}$ that demonstrated insignificant difference between $\mathrm{ETCO}_{2}$ value in patients who had clustered nursing interventions and patients who had rest periods.

Moreover, results of the present study illustrated that the most three physiological responses that are influenced significantly by the number of the clustered nursing care were mean systolic blood pressure, mean respiratory rate and mean oxygen saturation. These findings may be due to that stress induced by increasing number of clustered nursing care. In addition to the mechanically ventilated patients who experience pain related to their exposure to multiple procedures such as; suctioning, bathing, measuring central venous pressure, nasogastric tube insertion, obtaining arterial sample and routine sample at the same time which results in increasing systolic blood pressure value, respiratory rate value and decrease oxygen saturation value regarding the highest number of clustered nursing intervention performance.

This finding is in agreement with Holsti et al. $(2007)^{(28)}$ who demonstrated that the mean value of physiological responses increases significantly at clustered care after invasive multiple procedures compared to after rest.

Moreover, results of the current study showed that duration of measuring of vital signs lasted less than 5minutes, while duration of measuring central venous pressure lasted from 5-10 minutes and also it was found that duration of bathing lasted more than 10 minutes

There was a significant relationship between physiological responses and duration of procedures including duration of suctioning, repositioning, measuring central venous pressure, bathing, inserting nasogastric tube, obtaining blood sample, and performing chest tube care. These findings may be related to that pain intensity induced by increasing number of nursing care and exposure to multiple invasive procedures. These findings are in line with Puntillo et al. $(2001)^{(29)}$ and El Sharkawy et al. (2003) $)^{(30)}$ who reported that the most painful and distressing procedures were turning, suctioning and wound care for critically ill patients so that procedural pain varies considerably and is procedure specific.

Concerning the mean patient's systolic blood pressure, the current study result revealed that the mean patient's systolic blood pressure increased during and immediately after clustered nursing interventions performance compared to before performing clustered nursing interventions and return to baseline after 15 minutes from clustered nursing interventions performance. These findings may be due to the stress induced by the effect of clustered nursing interventions. This finding is supported by Valizadeh et al. (2014) ${ }^{(31)}$ who found that there was a significant statistical difference between clustered care performance and patient's blood pressure.

In relation to the mean patient's respiratory rate, results of the current study showed that the mean patient's respiratory rate increased during and then decreased immediately after clustered nursing care performance compared to before performing clustered nursing interventions and return to baseline after 15 minutes from clustered nursing interventions performance. This finding may be due to increase metabolic rate induced by the effect of clustered nursing care that leads to increase respiratory rate. It became shallow breathing during clustered nursing interventions performance and then patients become exhausted as clustered 
nursing care that lead to hypoventilation as a result of increasing concentration of carbon dioxide. This finding is in accordance with Genzler et el. $(2013)^{(23)}$ who indicated that there was significant statistical difference between clustered nursing care performance and patient's respiratory rate across before, during and after clustered nursing care performance.

With respect to the mean blood oxygen saturation, the current study results revealed that the mean blood oxygen saturation decreased during and immediately after the clustered care performed compared to before performing clustered nursing interventions then return to baseline after 15 minutes from clustered nursing interventions performance. This finding may be due to that stress induced by the effect of clustered nursing interventions leading to increase oxygen consumption. These findings are supported by Holsti et al (2007) ${ }^{(28)}$ and Valizadeh et al. (2014) ${ }^{(31)}$ who reported that there was a significant statistical difference between clustered nursing care performance and patient's oxygen saturation across before, during and after clustered nursing care performance.

Results of current study revealed that suctioning have an effect on respiratory rate and oxygen saturation of critically ill patients. Oxygen desaturation and tachypnea occurred during and after suctioning performance. These findings may be due to that tracheal suctioning is an invasive and blind procedure. Moreover, nurses took a long time in performing suctioning procedure without contest monitoring of oxygen saturation during procedure which resulted in oxygen

Results of the current study revealed that there was no significant correlation between duration of positioning and respiratory rate and oxygen saturation. This finding may be due to that critical care nurse did not take a lot of time to change patient's position. Thus, respiratory rate and oxygen saturation were not affected significantly by reposition. These findings are in opposition to Vollman et al. $(2012)^{(35)}$ and Scholes et al. (2013) ${ }^{(36)}$ who revealed that there was significant positive desaturation and tachypnea. This finding is in line with Afshari et al. (2014) ${ }^{(32)}$ who stated that low of knowledge of nurses about suctioning is the main cause for most of suction complications. In addition to, Asfour et al. $(2016)^{(33)}$ in a study titled nursing practices and oxygen desaturation in critically ill patients, reported that there were negative correlations between the duration of suctioning and oxygen saturation.

Body positioning affect oxygenation especially in critically ill patients as positioning and mobilization of patients contribute to improved oxygenation. Therefore, changing of patients' position remains a nursing intervention for ventilated patients not only to prevent pressure ulcers but also to improve circulation and oxygenation.

Results of current study illustrated that there was a negative correlation between duration of bathing and patient's oxygenation. This finding may be due to that improper water temperature and the long duration on supine position during bathing. Additionally, nurses did not monitor oxygen saturation during bathing so that duration of bathing affects patients' oxygenation especially in critically ill patients. This finding is in accordance with Enferm et al. $(2010)^{(34)}$ who found that heated and constant water temperature during the bed bath minimize the fall of $\mathrm{SpO}_{2}$ that occurs while handling patients during procedures. Similarly, Asfour et al. (2016) ${ }^{(33)}$ revealed that there was significant negative correlation between duration of bathing and oxygen saturation.

correlation between oxygen saturation and changing patients` positions.

As regard to the mean value of heart rate, the current study findings revealed that the mean percent change of heart rate immediately after clustered nursing interventions performance was significantly higher than the mean value before performing clustered nursing interventions.

Moreover, the mean value of heart rate after 15 minutes from clustered nursing interventions performance was significantly 
lower than the mean value immediately after clustered nursing interventions performance. This finding may be due to the stress and pain intensity induced by the effect of clustered nursing interventions. This finding is in agreement with Hamers et al. (2012) ${ }^{(37)}$ who found that there was a significant difference between heart rate and clustered nursing interventions performance.

Concerning the mean value of body temperature, the current study results revealed that there was no significant difference between body temperature and number of clustered nursing care performance. This finding may be due to that improper water temperature for bathing procedure which results in decreasing in patient's body temperature. This finding is in contrast with Holsti et al. $(2007)^{(28)}$ who found that clustering care is particularly stressful for critically ill patients that increases metabolic rate which results in increasing patients` body temperature.

\section{Conclusion}

- A significant relation between mean physiological responses and clustered nursing care including:

- Increased mean end tidal carbon dioxide, mean heart rate and mean systolic blood pressure immediately after clustered nursing care.

- Decreased mean oxygen saturation and mean respiratory rate immediately after clustered nursing care.

- There were significant difference between mean respiratory rate, mean systolic blood pressure and mean oxygen saturation regarding number of clustered nursing interventions among different study phases.

- There was a statistical significant relationship exists between physiological responses and duration of procedures including duration of performing central venous pressure measurement, suctioning, bathing, insertion of nasogastric tube, obtaining arterial samples, dressing on central venous catheter and dressing on peripheral vascular access, chest tube care, cardiopulmonary resuscitation and physiological responses including respiratory rate, oxygen saturation ,end tidal carbon dioxide and heart rate.

\section{Recommendations}

The main recommendations are:

- Non- clustered nursing interventions should be performed and applied in ICUs so that planned nursing interventions can be performed based on type and duration of procedures to allow periods of rest for critically ill patients to prevent physiological response alteration related to clustered nursing interventions performance.

- Fostering critical care nurses to attend workshops to be more knowledgeable about physiological responses and factors affecting it and to be more practicable about ICUs procedures.

- Adequate number of capnography monitor and portable pulse oximeters should be available in critical care settings.

- Find and test the feasibility of applying non- clustered nursing interventions performance in the ICUs. 
Table (1): Distribution of critically ill patients regarding to their characteristics

\begin{tabular}{|c|c|c|}
\hline Patient characteristics & $\begin{array}{l}\text { No. of patients } \\
\qquad(n=80)\end{array}$ & $\%$ \\
\hline $\begin{array}{l}\text { Intended study ICUs } \\
\text { Damanhur Medical National Institute } \\
\text { Alexandria Main University Hospital } \\
\text { - Casualty ICU I } \\
\text { - General ICU III }\end{array}$ & $\begin{array}{l}16 \\
25\end{array}$ & $\begin{array}{r}48.75 \\
20.0 \\
31.25\end{array}$ \\
\hline $\begin{array}{l}\text { Patients gender } \\
\text { Male } \\
\text { Female }\end{array}$ & $\begin{array}{l}49 \\
31\end{array}$ & $\begin{array}{l}61.25 \\
38.75\end{array}$ \\
\hline $\begin{array}{l}\text { Patients age } \\
18-39 \\
40-49 \\
50-60\end{array}$ & $\begin{array}{l}10 \\
19 \\
51\end{array}$ & $\begin{array}{l}12.5 \\
23.75 \\
63.75\end{array}$ \\
\hline Mean \pm SD & \multicolumn{2}{|c|}{$49.6 \pm 7.0$} \\
\hline $\begin{array}{l}\text { Length of stay } \\
<2 \text { weeks } \\
2- \\
3-4\end{array}$ & $\begin{array}{l}27 \\
33 \\
20\end{array}$ & $\begin{array}{l}33.75 \\
41.25 \\
25.0\end{array}$ \\
\hline Mean \pm SD & \multicolumn{2}{|c|}{$16.8 \pm 5.4$} \\
\hline $\begin{array}{l}\text { Duration of MV } \\
<2 \text { weeks } \\
2- \\
3-4\end{array}$ & $\begin{array}{c}47 \\
26 \\
7\end{array}$ & $\begin{array}{r}58.75 \\
32.5 \\
8.75\end{array}$ \\
\hline Mean \pm SD & \multicolumn{2}{|c|}{$13.8 \pm 4.9$} \\
\hline Medical diagnosis & & \\
\hline Cardiovascular disorders & 14 & 17.5 \\
\hline Neurological disorders & 28 & 35 \\
\hline Renal disorders & 12 & 15 \\
\hline Endocrine disorders & 16 & 20 \\
\hline Gastrointestinal disorder & 6 & 7.5 \\
\hline Others & 4 & 5 \\
\hline
\end{tabular}


Table (2): Distribution of critically ill patients according to number of clustered nursing interventions in the intended study ICUs

\begin{tabular}{|c|c|c|c|c|c|c|c|c|c|}
\hline \multirow{3}{*}{$\begin{array}{l}\text { Number of } \\
\text { clustered } \\
\text { nursing } \\
\text { interventions }\end{array}$} & \multicolumn{6}{|c|}{ Unit } & \multirow{3}{*}{ MCP } & \multirow{2}{*}{\multicolumn{2}{|c|}{ Total }} \\
\hline & \multicolumn{2}{|c|}{ ICU Damanhur } & \multicolumn{2}{|c|}{ ICU Alex unit I } & \multicolumn{2}{|c|}{ ICU Alex unit III } & & & \\
\hline & No & $\%$ & No & $\%$ & No & $\%$ & & No & $\%$ \\
\hline Low (0-7) & 2 & $5.1 \%$ & 1 & $6.3 \%$ & 0 & $0.0 \%$ & & 3 & $3.8 \%$ \\
\hline High (8-15) & 37 & $94.9 \%$ & 15 & $93.8 \%$ & 25 & $100.0 \%$ & 0.483 & 77 & $\begin{array}{c}96.3 \\
\%\end{array}$ \\
\hline $\begin{array}{l}\text { Range } \\
\text { Mean } \pm \text { SD } \\
\text { Median }\end{array}$ & \multicolumn{2}{|c|}{$\begin{array}{c}7-13 \\
0.9 \pm 1.6 \\
11.0\end{array}$} & \multicolumn{2}{|c|}{$\begin{array}{c}7-15 \\
10.8 \pm 1.8 \\
11.0\end{array}$} & \multicolumn{2}{|c|}{$\begin{array}{c}8-13 \\
10.8 \pm 1.3 \\
11.0\end{array}$} & & \multicolumn{2}{|c|}{$\begin{array}{c}7-15 \\
10.9 \pm 1.5 \\
11.0 \\
\end{array}$} \\
\hline
\end{tabular}

MCP: Mont Carlo exact probability

Table (3): Relationship between number of clustered nursing interventions and patients' characteristics

\begin{tabular}{|c|c|c|c|c|c|}
\hline \multirow[t]{3}{*}{ Characteristics } & \multicolumn{4}{|c|}{ Number of clustered nursing interventions } & \multirow{3}{*}{$M C P$} \\
\hline & \multicolumn{2}{|c|}{$\operatorname{Low}(0-7)$} & \multicolumn{2}{|c|}{ High (8-15) } & \\
\hline & No & $\%$ & No & $\%$ & \\
\hline $\begin{array}{l}\text { Age in years } \\
18-39 \\
40-49 \\
50-60\end{array}$ & $\begin{array}{l}0 \\
1 \\
2\end{array}$ & $\begin{array}{l}0.0 \% \\
5.3 \% \\
3.9 \%\end{array}$ & $\begin{array}{l}10 \\
18 \\
49 \\
\end{array}$ & $\begin{array}{c}100.0 \% \\
94.7 \% \\
96.1 \%\end{array}$ & 0.772 \\
\hline $\begin{array}{l}\text { Sex } \\
\text { Male } \\
\text { Female }\end{array}$ & $\begin{array}{l}1 \\
2\end{array}$ & $\begin{array}{l}2.0 \% \\
6.5 \%\end{array}$ & $\begin{array}{l}48 \\
29\end{array}$ & $\begin{array}{l}98.0 \% \\
93.5 \%\end{array}$ & 0.312 \\
\hline $\begin{array}{l}\text { Duration of MV } \\
<2 \text { weeks } \\
2- \\
3-4 \\
\end{array}$ & $\begin{array}{l}2 \\
0 \\
1\end{array}$ & $\begin{array}{c}4.3 \% \\
0.0 \% \\
14.3 \%\end{array}$ & $\begin{array}{c}45 \\
26 \\
6\end{array}$ & $\begin{array}{c}95.7 \% \\
100.0 \% \\
85.7 \%\end{array}$ & 0.202 \\
\hline $\begin{array}{l}\text { Length of stay } \\
<2 \text { weeks } \\
2- \\
3-4\end{array}$ & $\begin{array}{l}1 \\
0 \\
2\end{array}$ & $\begin{array}{c}3.7 \% \\
0.0 \% \\
10.0 \%\end{array}$ & $\begin{array}{l}26 \\
33 \\
18\end{array}$ & $\begin{array}{c}96.3 \% \\
100.0 \% \\
90.0 \%\end{array}$ & 0.178 \\
\hline $\begin{array}{l}\text { Diagnosis } \\
\text { Cardiac } \\
\text { Renal } \\
\text { Neurological } \\
\text { Endocrine } \\
\text { GIT } \\
\text { Others } \\
\end{array}$ & $\begin{array}{l}0 \\
0 \\
2 \\
0 \\
1 \\
0\end{array}$ & $\begin{array}{c}0.0 \% \\
0.0 \% \\
7.1 \% \\
0.0 \% \\
16.7 \% \\
0.0 \%\end{array}$ & $\begin{array}{c}14 \\
12 \\
26 \\
16 \\
5 \\
4\end{array}$ & $\begin{array}{c}100.0 \% \\
100.0 \% \\
92.9 \% \\
100.0 \% \\
83.3 \% \\
100.0 \%\end{array}$ & $0.001 *$ \\
\hline
\end{tabular}


Table (4): Mean value of physiological parameters status before, during and after clustered nursing interventions performance

\begin{tabular}{|c|c|c|c|c|c|c|c|c|c|c|c|c|}
\hline \multirow[t]{2}{*}{$\begin{array}{l}\text { Physiological } \\
\text { response }\end{array}$} & \multicolumn{2}{|c|}{$\begin{array}{c}\mathrm{ETCO}_{2} \\
(\mathrm{mmHg})\end{array}$} & \multicolumn{2}{|c|}{$\mathbf{R R}(\mathbf{c} / \mathbf{m})$} & \multicolumn{2}{|c|}{$\mathrm{SPO}_{2}(\%)$} & \multicolumn{2}{|c|}{ HR (b/m) } & \multicolumn{2}{|c|}{ SBP $(\mathrm{mmHg})$} & \multicolumn{2}{|c|}{$\begin{array}{c}\text { Body } \\
\text { temperature } \\
\left({ }^{\circ} \mathbf{C}\right)\end{array}$} \\
\hline & Mean & SD & Mean & SD & Mean & SD & Mean & SD & Mean & SD & Mean & SD \\
\hline $\begin{array}{l}\text { Before } \\
\text { nursing } \\
\text { intervention }\end{array}$ & 27.8 & 9.5 & 20.3 & 4.9 & 98.4 & 1.8 & 94.3 & 18.7 & 130.4 & 27.0 & 36.9 & 0.5 \\
\hline $\begin{array}{l}\text { During } \\
\text { nursing } \\
\text { intervention } \\
5 \mathrm{~min}\end{array}$ & 31.5 & 20.4 & 19.8 & 4.9 & 97.7 & 2.0 & 96.3 & 19.4 & 130.4 & 27.1 & 36.9 & 0.6 \\
\hline $\begin{array}{l}\text { During } \\
\text { nursing } \\
\text { intervention } \\
10 \mathrm{~min}\end{array}$ & 32.0 & 10.2 & 18.2 & 4.5 & 96.2 & 2.4 & 99.5 & 21.2 & 130.2 & 26.9 & 37.1 & 0.5 \\
\hline $\begin{array}{l}\text { Immediately } \\
\text { after nursing } \\
\text { intervention }\end{array}$ & 37.7 & 11.2 & 16.3 & 3.9 & 92.3 & 3.7 & 103.4 & 22.5 & 137.5 & 28.0 & 36.7 & 0.5 \\
\hline $\begin{array}{l}15 \mathrm{~min} \text { after } \\
\text { nursing } \\
\text { intervention }\end{array}$ & 27.3 & 9.8 & 21.5 & 4.5 & 98.1 & 1.9 & 95.2 & 19.0 & 130.3 & 27.4 & 36.9 & 0.4 \\
\hline $\mathrm{P} 1$ & \multicolumn{2}{|c|}{$0.001 *$} & \multicolumn{2}{|c|}{$\frac{1}{0.002 *}$} & \multicolumn{2}{|c|}{$0.028^{*}$} & \multicolumn{2}{|c|}{$0.022 *$} & \multicolumn{2}{|c|}{$0.005^{*}$} & \multicolumn{2}{|c|}{0.086} \\
\hline $\mathrm{P} 2$ & \multicolumn{2}{|c|}{$0.001 *$} & \multicolumn{2}{|c|}{$0.001 *$} & \multicolumn{2}{|c|}{$0.030 *$} & \multicolumn{2}{|c|}{$0.020 *$} & \multicolumn{2}{|c|}{$0.004 *$} & \multicolumn{2}{|c|}{0.086} \\
\hline
\end{tabular}

$\mathrm{ETCO}_{2}$ : End Tidal Carbon Dioxide

RR: Respirator Rate

SBP: Systolic Blood Pressure

$\mathrm{SPO}_{2}$ : Oxygen Saturation

HR: Heart Rate

P1: P value for paired t-test for comparing between before starting clustered nursing interventions with immediately after clustered nursing interventions performance

P2: P value for paired t-test for comparing between immediately after clustered nursing interventions performance with after 15 min from clustered nursing interventions end. * Statistically significant at $\mathrm{p} \leq 0.05$ 


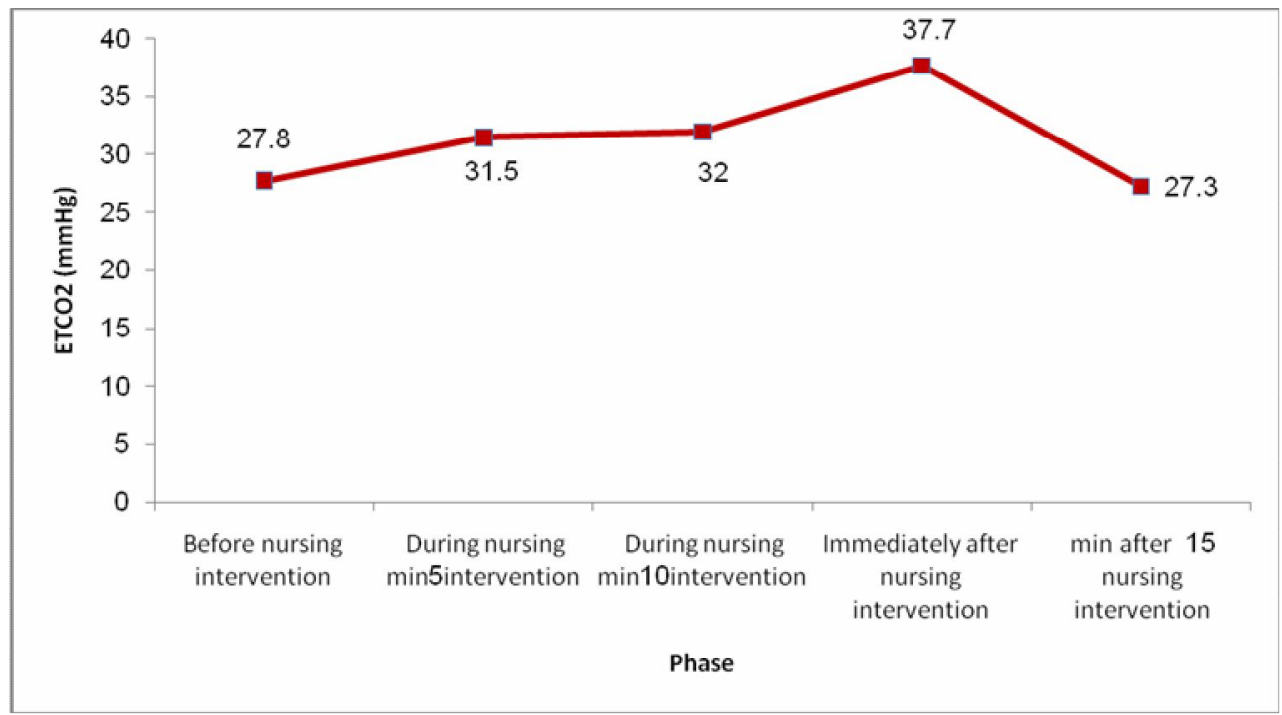

Figure (1): Mean value of end tidal carbon dioxide before, during and after clustered nursing interventions performance

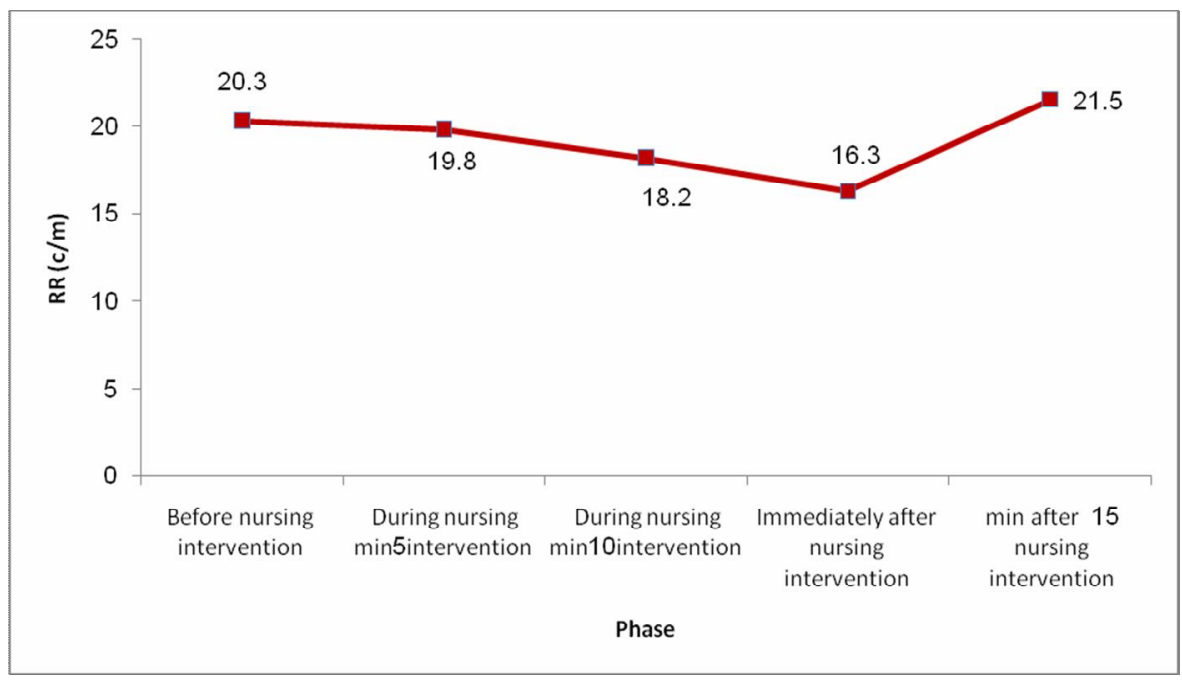

Figure (2): Mean value of respiratory rate before, during and after clustered nursing interventions performance 


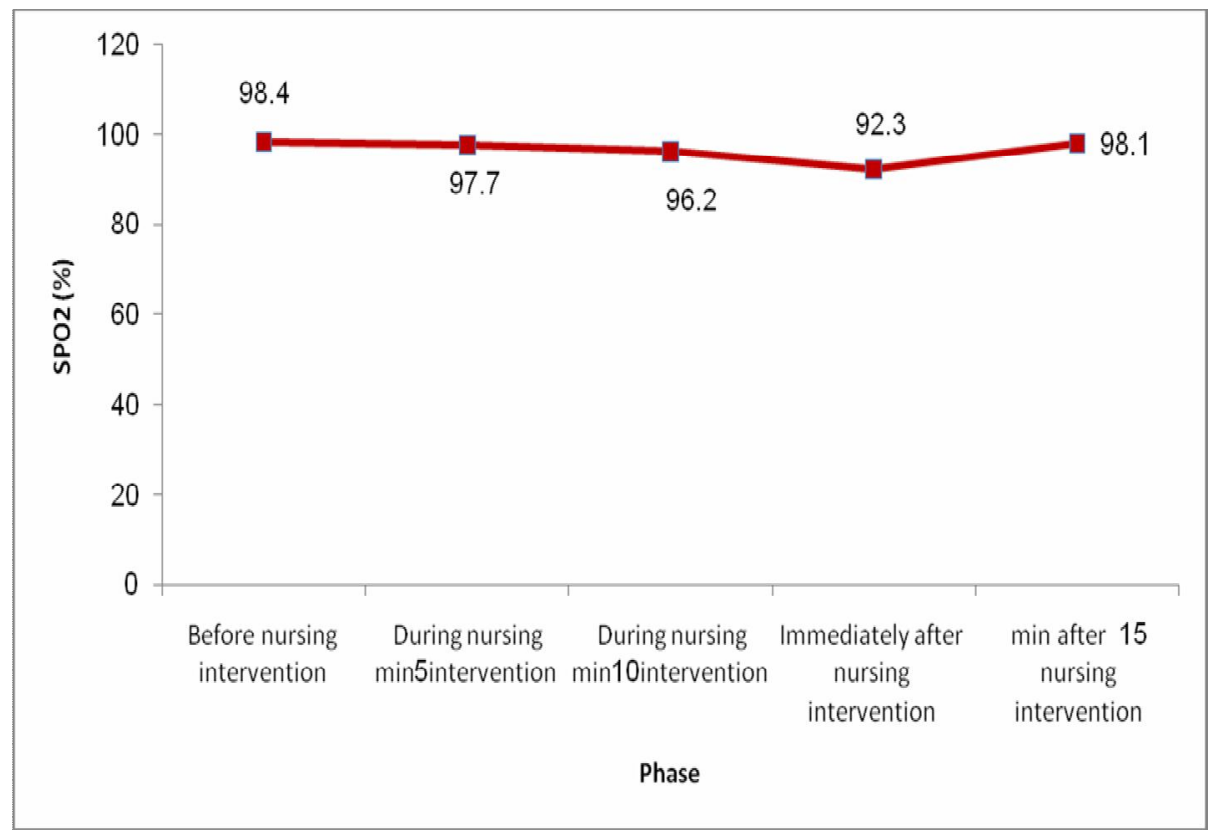

Figure (3): Mean value of oxygen saturation before, during and after clustered nursing interventions performance

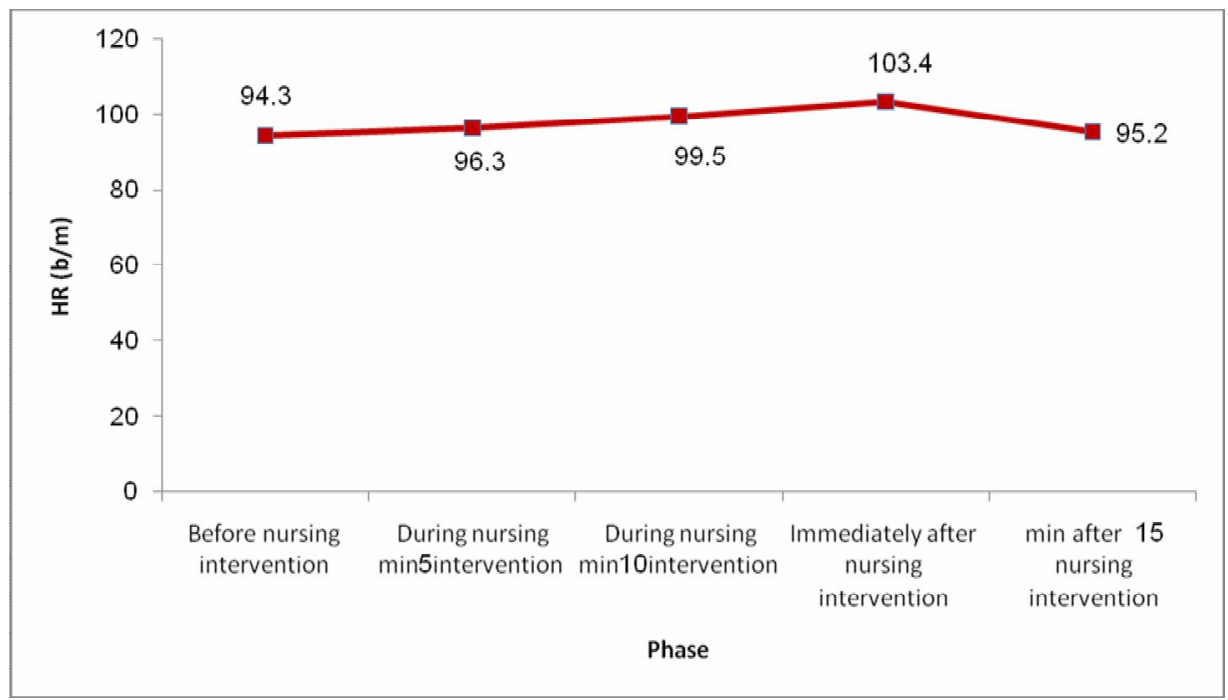

Figure (4): Mean value of heart rate before, during and after clustered nursing interventions performance 
Nursing Interventions and Mechanically Ventilated Patients

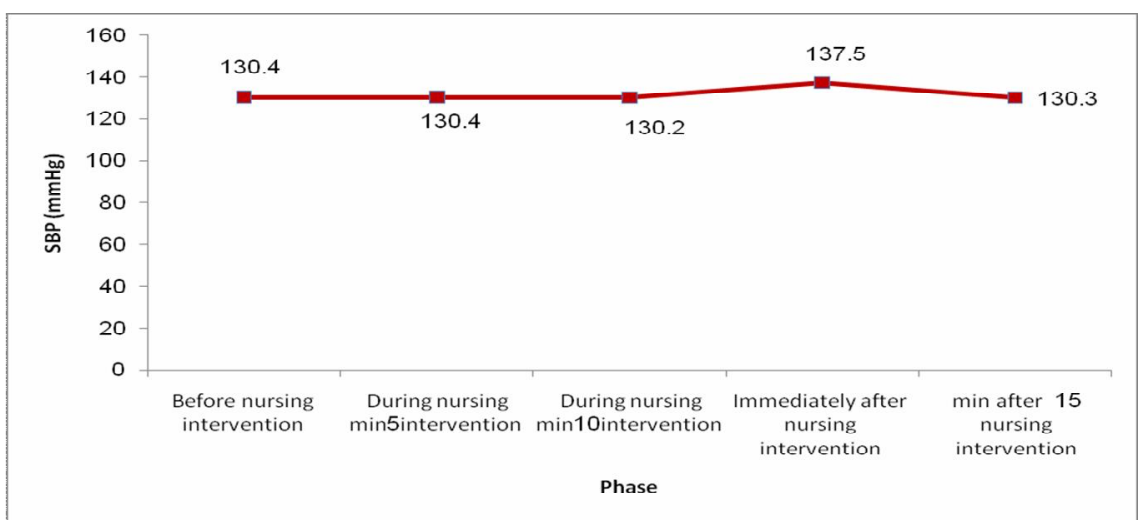

Figure (5): Mean value of systolic blood pressure before, during and after clustered nursing interventions performance

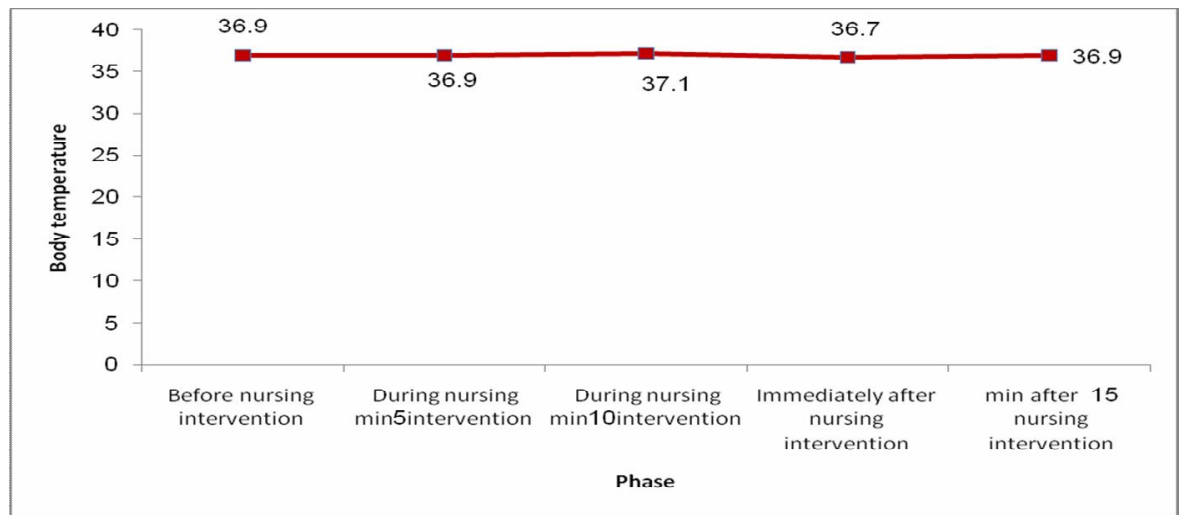

Figure (6): Mean value of body temperature before, during and after clustered nursing interventions performance

Table (5): Relationship between physiological responses and the number of clustered nursing interventions

\begin{tabular}{|c|c|c|c|c|c|}
\hline \multirow{3}{*}{ Physiological responses } & \multicolumn{4}{|c|}{ Number of clustered nursing interventions } & \multirow{3}{*}{$\begin{array}{c}\mathbf{t} \\
(\mathbf{P})\end{array}$} \\
\hline & \multicolumn{2}{|c|}{ Low (0-7) } & \multicolumn{2}{|c|}{ High (8-15) } & \\
\hline & Mean & SD & Mean & SD & \\
\hline ETCO $2 \mathrm{~mm} / \mathrm{Hg}$ & 36.23 & 4.62 & 31.08 & 10.31 & $1.6(0.328)$ \\
\hline $\mathrm{RR} \mathrm{c} / \mathrm{m}$ & 17.20 & 1.91 & 19.31 & 4.27 & $2.0(0.050)^{*}$ \\
\hline $\mathrm{SPO} 2 \%$ & 98.67 & .70 & 96.44 & 1.91 & $2.9(0.003)^{*}$ \\
\hline $\mathrm{HR} b / \mathrm{m}$ & 99.80 & 14.12 & 97.66 & 20.06 & $0.28(0.827)$ \\
\hline $\mathrm{SBP} \mathrm{mm} / \mathrm{Hg}$ & 130.89 & 26.95 & 154.13 & 25.22 & $3.6(0.002)^{*}$ \\
\hline Body Temperature & 37.0 & 0.5 & 36.90 & 0.42 & $1.4(0.096)$ \\
\hline $\begin{array}{l}\mathrm{ETCO}_{2} \text { : End Tidal Carbon D } \\
\text { HR: Heart Rate } \\
\text { t: independent samples t-test }\end{array}$ & \multicolumn{5}{|c|}{$\begin{array}{ll}\text { RR: Respiratory Rate } & \mathrm{SPO}_{2} \text { : Oxygen Saturation } \\
\text { SBP: Systolic Blood Pressure } & \end{array}$} \\
\hline
\end{tabular}


Table (6.a): Duration of procedures performed to the critically ill patients by critical care nurses

\begin{tabular}{|c|c|c|c|c|c|c|c|c|}
\hline \multirow{2}{*}{ Procedure } & \multicolumn{2}{|c|}{$<5 \mathrm{~min}$} & \multicolumn{2}{|c|}{ 5-10 min } & \multicolumn{2}{|c|}{$>10 \mathrm{~min}$} & \multirow{2}{*}{ Mean } & \multirow{2}{*}{ SD } \\
\hline & No & $\%$ & No & $\%$ & No & $\%$ & & \\
\hline Vital signs & 74 & $92.5 \%$ & 6 & $7.5 \%$ & 0 & $0.0 \%$ & 3.88 & .51 \\
\hline $\begin{array}{l}\text { Central venous pressure } \\
\text { measurement }\end{array}$ & 0 & $0.0 \%$ & 67 & $83.8 \%$ & 0 & $0.0 \%$ & 4.95 & 2.35 \\
\hline Tracheal suctioning & 12 & $15.0 \%$ & 50 & $62.5 \%$ & 0 & $0.0 \%$ & 2.31 & .89 \\
\hline Oropharngeal suctioning & 22 & $27.5 \%$ & 38 & $47.5 \%$ & 0 & $0.0 \%$ & 2.11 & 1.28 \\
\hline Nasogastric tube insertion & 2 & $2.5 \%$ & 10 & $12.5 \%$ & 0 & $0.0 \%$ & .69 & 1.69 \\
\hline Enteral Feeding & 10 & $12.5 \%$ & 43 & $53.8 \%$ & 0 & $0.0 \%$ & 2.70 & 2.17 \\
\hline Gastric Lavage & 1 & $1.3 \%$ & 5 & $6.3 \%$ & 0 & $0.0 \%$ & .28 & .99 \\
\hline Routine sample & 7 & $8.75 \%$ & 38 & $47.5 \%$ & 0 & $0.0 \%$ & 3.13 & 2.96 \\
\hline Arterial Blood Gas sample & 20 & $25.0 \%$ & 34 & $30.0 \%$ & 0 & $0.0 \%$ & 2.68 & 2.07 \\
\hline Random blood sugar & 64 & $80.0 \%$ & 0 & $0.0 \%$ & 0 & $0.0 \%$ & 1.14 & .78 \\
\hline Culture & 10 & $12.5 \%$ & 8 & $10.0 \%$ & 2 & $2.5 \%$ & 1.35 & 3.11 \\
\hline Bed Bath & 0 & $0.0 \%$ & 11 & $13.8 \%$ & 36 & $45.0 \%$ & 8.41 & 7.54 \\
\hline Mouth care & 30 & $37.5 \%$ & 5 & $6.3 \%$ & 0 & $0.0 \%$ & 1.28 & 1.53 \\
\hline Endotracheal tube care & 52 & $65.0 \%$ & 0 & $0.0 \%$ & 0 & $0.0 \%$ & 1.51 & 1.19 \\
\hline Tracheotomy tube care & 4 & $5.0 \%$ & 20 & $25 \%$ & 0 & $0.0 \%$ & .81 & 1.31 \\
\hline $\begin{array}{l}\text { Dressing on central venous } \\
\text { catheter }\end{array}$ & 65 & $81.3 \%$ & 4 & $5 \%$ & 0 & $0.0 \%$ & 2.15 & 1.14 \\
\hline Dressing on wound & 0 & $0.0 \%$ & 10 & $12.5 \%$ & 8 & $10 \%$ & 1.11 & 2.42 \\
\hline $\begin{array}{l}\text { Dressing on peripheral vascular } \\
\text { access }\end{array}$ & 4 & $5.0 \%$ & 1 & $1.3 \%$ & 0 & $0.0 \%$ & .20 & .82 \\
\hline Chest tube care & 4 & $5.0 \%$ & 4 & $5.0 \%$ & 0 & $0.0 \%$ & .50 & 1.58 \\
\hline $\begin{array}{l}\text { Reposition Range of motion } \\
\text { exercise }\end{array}$ & 0 & $0 \%$ & 51 & $63.8 \%$ & 24 & $30 \%$ & 4.98 & 2.04 \\
\hline Medication administration & 0 & $0.0 \%$ & 35 & $43.8 \%$ & 6 & $7.5 \%$ & 3.84 & 4.24 \\
\hline Enema & 2 & $2.5 \%$ & 6 & $7.5 \%$ & 0 & $0.0 \%$ & .54 & 1.67 \\
\hline Cardiopulmonary resuscitation & 0 & $0.0 \%$ & 0 & $0.0 \%$ & 2 & $2.5 \%$ & .20 & 1.30 \\
\hline
\end{tabular}


Table (6.b): Correlation between duration of procedures performed to patients by critical care nurses and physiological responses

\begin{tabular}{|c|c|c|c|c|c|c|c|c|c|c|c|c|}
\hline \multirow{3}{*}{$\begin{array}{l}\text { Duration of } \\
\text { procedure }\end{array}$} & \multicolumn{12}{|c|}{ Physiological responses } \\
\hline & \multicolumn{2}{|c|}{$\mathrm{ETCO}_{2}$} & \multicolumn{2}{|c|}{ RR } & \multicolumn{2}{|c|}{$\mathrm{SPO}_{2}$} & \multicolumn{2}{|c|}{ HR } & \multicolumn{2}{|c|}{ SBP } & \multicolumn{2}{|c|}{ Body Temp } \\
\hline & $\mathbf{r}$ & $\mathbf{p}$ & $\mathbf{r}$ & $\mathbf{p}$ & $\mathbf{R}$ & $\mathbf{p}$ & $\mathbf{r}$ & $\mathbf{p}$ & $\mathbf{r}$ & $\mathbf{p}$ & $\mathbf{r}$ & $\mathbf{p}$ \\
\hline \begin{tabular}{|l|} 
Vital signs \\
\end{tabular} & -.042 & .709 & -.074 & .512 & -.056 & .623 & -.054 & .634 & .083 & .462 & .043 & .703 \\
\hline $\begin{array}{l}\text { Central venous } \\
\text { pressure } \\
\text { measurement }\end{array}$ & -.192 & .089 & -.327 & .003 & .127 & .261 & .024 & .833 & -.044 & .695 & $-.113-$ & .317 \\
\hline $\begin{array}{l}\text { Tracheal } \\
\text { suctioning }\end{array}$ & .166 & .140 & .236 & .035 & .228 & .042 & .012 & .919 & .121 & .286 & $-.186-$ & .098 \\
\hline $\begin{array}{l}\text { Oropharngeal } \\
\text { suctioning }\end{array}$ & .179 & .112 & -.006 & .956 & -.044 & .700 & 099 & .380 & -.073 & .522 & .164 & .145 \\
\hline $\begin{array}{l}\text { Nasogastric tube } \\
\text { insertion }\end{array}$ & .160 & .156 & -.122 & .283 & -.185 & .100 & 243 & .030 & .109 & .335 & .255 & .220 \\
\hline \begin{tabular}{|l|} 
Enteral Feeding \\
\end{tabular} & -.085 & .451 & .095 & .404 & -.039 & .730 & -.162 & .151 & -.039 & .731 & .059 & .601 \\
\hline Gastric Lavage & .209 & .062 & .011 & .921 & -.014 & .900 & .101 & .373 & .202 & .072 & $\begin{array}{l}-.084- \\
\end{array}$ & .458 \\
\hline Routine sample & -.089 & .431 & -.124 & .274 & -.223 & .047 & .110 & .332 & -.049 & .668 & $-.137-$ & .224 \\
\hline $\begin{array}{l}\text { Arterial Blood } \\
\text { Gas sample }\end{array}$ & -.158 & .161 & .077 & .498 & -.060 & .599 & -.253 & .023 & -.156 & .167 & $-.131-$ & .247 \\
\hline $\begin{array}{l}\text { Random blood } \\
\text { sugar }\end{array}$ & -.064 & .571 & .023 & .836 & .056 & .620 & -.043 & .708 & .075 & .509 & .082 & .471 \\
\hline Culture & -.139 & .220 & -.045 & .690 & -.071 & .530 & .022 & .843 & .055 & .625 & $-.067-$ & .557 \\
\hline Bed Bath & .129 & .256 & .117 & .303 & -.256 & .022 & .114 & .316 & .132 & .242 & .136 & .229 \\
\hline Mouth care & .204 & .069 & .057 & .616 & -.050 & .663 & .114 & .357 & .133 & .241 & .184 & .101 \\
\hline $\begin{array}{l}\text { Endotracheal } \\
\text { tube care }\end{array}$ & .057 & .618 & .014 & .905 & -.077 & .497 & .095 & .403 & -.181 & .107 & $-.086-$ & .449 \\
\hline $\begin{array}{l}\text { Tracheotomy } \\
\text { tube care }\end{array}$ & -.029 & .802 & .034 & .762 & -.045 & .694 & -.068 & .548 & 039 & .733 & .064 & .571 \\
\hline $\begin{array}{l}\text { Dressing on } \\
\text { central venous } \\
\text { catheter }\end{array}$ & -.237 & .034 & -.069 & .543 & -.097 & .394 & -.013 & .906 & .008 & .946 & $-001-$ & .992 \\
\hline $\begin{array}{l}\text { Dressing on } \\
\text { wound }\end{array}$ & -.188 & 095 & .077 & .500 & -.013 & .906 & -.141 & .211 & .135 & .233 & .097 & .391 \\
\hline \begin{tabular}{|l|} 
Dressing on \\
peripheral \\
vascular access
\end{tabular} & .213 & 058 & .106 & .349 & -.052 & .650 & .076 & .502 & -.226 & .043 & .126 & .264 \\
\hline Chest tube care & .166 & .142 & .071 & .532 & -.028 & .803 & .311 & .005 & .000 & 1.000 & .041 & .719 \\
\hline \begin{tabular}{|l|} 
Reposition \& \\
Range of motion \\
exercise
\end{tabular} & .112 & .322 & .090 & .428 & .118 & .297 & -.035 & .755 & .004 & .973 & .231 & .390 \\
\hline \begin{tabular}{|l} 
Medication \\
administration
\end{tabular} & .033 & .772 & -.039 & .732 & -.001 & .996 & .110 & .332 & -.278 & .013 & .165 & .143 \\
\hline Enema & .294 & .008 & .140 & .217 & -.062 & .583 & .155 & .170 & .068 & .547 & $-.052-$ & .644 \\
\hline \begin{tabular}{|l}
$\begin{array}{l}\text { Cardiopulmonary } \\
\text { resuscitation }\end{array}$ \\
\end{tabular} & -.185 & .097 & -.098 & .386 & -.154 & .172 & -.311 & .165 & -.121 & .284 & $-.154-$ & .172 \\
\hline
\end{tabular}




\section{References}

1. American Association of Critical-Care Nurses: Member services: Certification. Available at: http://www.aacn.org/AACN/MemShip.nsf.

Accessed on April 20, 2002.

2. Wendon J. Critical care "normality": individualized versus protocolized care. Critical Care Med. 2010; 38(10):590-9.

3. Kavanagh B, Meyer L. Normalizing physiological variables in acute illness: five reasons for caution. Intensive Care Med. 2005; 31(9):1161-7.

4. American Psychological Association, Stress in America 2010, Key Findings, 2010. Available at: www.apa.org/news/press/releases/stress/ke y-findings.pdf.

5. Aiken L, Clarke S, Sloan D. Hospital staffing, organization, and quality of care: Cross-national findings. Nurs Outlook .2002; 50: 187-94.

6. Sochalski J. Quality of Care, Nurse Staffing, and Patient Outcomes. Policy, Politics, \& Nursing Practice (PPNP) journal. 2001; 2(1):9-18.

7. Estabrooks C, Midodzi W, Cummings G. The impact of hospital nursing characteristics on 30-day mortality. Nursing Research. 2005; 54: 74-84.

8. Estabrooks $\mathrm{C}$, Chong $\mathrm{H}$, Brigidear $\mathrm{K}$. Profiling Canadian nurses' preferred knowledge sources for clinical practice. Canadian Journal of Nursing Research 2005; 37: 118-40.

9. Adel A, Rabie M. Patterns of admitted cases to Respiratory Intensive Care Unit at Zagazig University Hospitals, Egypt. Egyptian Journal of Chest Diseases and Tuberculosis. 2013 Oct; 62(4): 661-8.

10. Kahn J, Goss C. Hospital volume and the outcomes of mechanical ventilation New England Journal of Medicine. 2006; 355 (1):41-50.

11. Sevransky J, Checkley W, Herrera P, Pickering B, Barr J. Protocols and Hospital Mortality in Critically Ill Patients: The United States Critical Illness and Injury
Trials Group Critical Illness Outcomes Study. Critical Care Medicine Journal 2015. Oct; 43(10):2076-84.

12. Rosenbaum S, Thompson D. Organizational and management ethics in the intensive care unit. Critical Care Medicine Journal. 2007; 35(2):529 -35.

13. David H, Lindner D. Society of Critical Care Medicine. Critical Care Units: A Descriptive Analysis. $1^{\text {st }}$ ed. Des Plaines, IL: Society of Critical Care Medicine; 2005.

14. US Department of Health and Human Services. Health Resources and Services Administration Report to Congress. The Critical Care Workforce: A Study of the Supply and Demand for Critical Care Physicians. May 2006. Availableat:http://bhpr.hrsa.gov/healthworf orce/reports/studycriticalcarephys.pdf. Accessed on January 4, 2012.

15. Bulechek G, Butcher H, Dochterman J. Cerebral edema management. Nursing Interventions Classifications. $5^{\text {th }}$ ed. USA: Mosby/Elsevier. 2008:207-8.

16. HickeyJ. The Clinical Practice of Neurological and Neurosurgical Nursing. Philadelphia, PA: Lippincott William \& Wilkins; 2003.

17. Br. J. Anaesth. Recent advances in gas exchange measurement in intensive care patients. 2003; 91 (1): 120-31.

18. MitchellP. Intracranial hypertension: influence of nursing care activities. Nurs Clin North Am. 2002; 21: 563-76.

19. Motzer S, Hertig V .Stress: stress response and health. Nursing Clinics of North America. 2004; 39: 1-17.

20. Faisy C, Gerot E, Diehl J, Iftimovici E, Fagon $\mathrm{H}$.Clinically significant gastrointestinal bleeding in critically ill patients with and without stress ulcer prophylaxis. Intensive care Med 2003; 29:1306-13.

21. Saba V. Clinical care classification (CCC) manual: A guide to nursing documentation. $2^{\text {nd }}$ ed. New York: Springer Publishing.2012. 
22. Szabo C, Grap M, Munro C, Starkweather A, Merchant R. The effect of oral care on intracranial pressure in critically ill adults. Journal of the American Association of Neuroscience Nurses 2014; 46(6):321-9.

23. Genzler R, Johnson P, Ghildayal N. End tidal carbon dioxide as a measure of stress response to clustered nursing intervention in neurologic patients. American Journal of Critical Care 2013; 22(3): 239-45.

24. Al Sutari M, Abdalrahim M, Mansour A, Ayasrah S. Pain among mechanically ventilated patients in critical care units. Journal of research in medical science 2014 Aug; 19(8): 726-32.

25. Max A, Puntillo K, Timsit J, Vignoud L, Chanques G. Determinants of Procedural Pain Intensity in the Intensive Care Unit. American Journal of Respiratory and Critical Care Medicine. 2014: 189(1):3947.

26. Olson D, McNett M, Lewis L, Riemen K, Bautista C. Effects of Nursing Interventions on Intracranial Pressure. American Journal of Critical Care. 2013; 22: 431-38.

27. Ugras G, S Yuksels. Factors Affecting Intracranial Pressure and Nursing Interventions. Jacobs Journal of Nursing and Care 2014:1(1): 1-6.

28. Holsti L, Grunau R, Oberlander T, Whitfield M. Prior pain induces heightened motor responses during clustered care in preterm infants in the NICU. Early Human Development. 2007; 81(3):293-302.

29. Puntillo K, White C, Morris A, Perdue S, Stanik-Hutt J, Thompson C. Patients' perceptions and responses to procedural pain: Results from Thunder Project II. American Journal of Critical Care. 2001;10:238-51

30. El Sharkawy F, Attia A. Magnitude and dimension of procedural pain in critically ill patients. Alexendria Journal of anesthesia and Intensive care 2003; $6(2): 130-41$.

31. Valizadeh L, Avazeh $\mathrm{M}$, Bagher M, Asghari M.Comparison of Clustered Care with Three and Four Procedures on Physiological Responses of Preterm
Infants. Journal of Caring Sciences. 2014; 3(1):1-10.

32. Afshari A, Safari M, Oshvandi K, Soltanian A. The Effect of the Open and Closed System Suctions on Cardiopulmonary Parameters: Time and Costs in Patients Under Mechanical Ventilation. Nurs Midwifery Stud. 2014 June; 3(2): 14097.

33. Asfour H. Oxygen Desaturation and Nursing Practices in Critically Ill Patients. IOSR Journal of Nursing and Health Science.2016 Mar; 5(2): 85-9.

34. Enferm R. Oliveira A, Lima D. Rev E. Evaluation of bed bath in critically ill patients: impact of water temperature on the pulse oximetry variation. Acta Paul Enferm 2010: 4(44); 1039-45.

35. Vollman K. Hemodynamic instability: is it really a barrier to turning critically ill patients? Critical Care Nurse 2012:32(1); 7-10.

36. Scholes J, Albarran J. Nursing in Critical Care. British Association of Critical Care Nurses.2013: 18(1); 20.

37. Hamers J, Jeitziner M, Schwendimann R, Rohrer O, Hantikainen V, Jakob S. Assessment of pain in sedated and mechanically ventilated patients: An observational study. Acta Anaesthesiol Scand. 2012; 56: 645-54. 